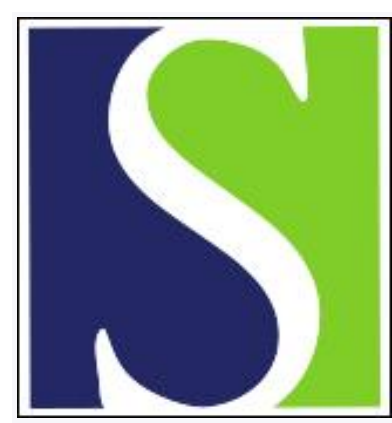

Scand J Work Environ Health 2001;27(4):227-232

https://doi.org/10.5271/sjweh.609

Issue date: Aug 2001

Exposure to titanium dioxide and risk of lung cancer in a population-based study from Montreal

by Boffetta P, Gaborieau V, Nadon L, Parent M-E, Weiderpass E, Siemiatycki J

Affiliation: International Agency for Research on Cancer, 150 cours Albert-Thomas, 69008 Lyon, France. boffetta@iarc.fr

Key terms: epidemiology; exposure; lung cancer; lung neoplasms; occupational exposure; population-based study; risk; titanium dioxide

This article in PubMed: www.ncbi.nlm.nih.gov/pubmed/11560336 


\title{
Exposure to titanium dioxide and risk of lung cancer in a population-based study from Montreal
}

\author{
by Paolo Boffetta, MD, ${ }^{1,2}$ Valerie Gaborieau, ${ }^{1}$ Louise Nadon, $P h D,{ }^{3}$ Marie-Elise Parent, PhD, ${ }^{3}$ Elisabete \\ Weiderpass, MD, ${ }^{2,4}$ Jack Siemiatycki, PhD ${ }^{3,5}$
}

\begin{abstract}
Boffetta P, Gaborieau V, Nadon L, Parent M-E, Weiderpass E, Siemiatycki J. Exposure to titanium dioxide and risk of lung cancer in a population-based study from Montreal. Scand J Work Environ Health 2001;27(4):227232.
\end{abstract}

\begin{abstract}
Objectives This study assessed the lung cancer risk from exposure to titanium dioxide, an important pigment with limited evidence of carcinogenicity in experimental animals but sparse data for humans.

Methods The risk of lung cancer among residents in Montreal, Canada, was analyzed, including 857 histologically confirmed cases of lung cancer diagnosed during 1979-1985 among men aged 35—70 years and a group of referents comprising 533 randomly selected, healthy residents and 533 persons with cancer in organs other than the lung. Exposure to titanium dioxide and other titanium compounds was assessed by a team of industrial hygienists on the basis of a detailed occupational questionnaire.

Results Thirty-three cases and 43 referents were classified as exposed to titanium dioxide. The odds ratio was 0.9 [95\% confidence interval (95\% CI) $0.5-1.5]$. No trend was apparent according to the estimated frequency, level, or duration of exposure. The odds ratio was 1.0 (95\% CI $0.3-2.7)$ for medium or high exposure for at least 5 years. Few subjects were classified as exposed to titanium dioxide fumes or to other titanium compounds, but the risk of lung cancer was nonsignificantly increased for exposure to these agents.

Conclusions Although misclassification of exposure and low exposure prevalence might have resulted in false negative results, this study does not suggest that occupational exposure to titanium dioxide increases the risk of lung cancer.
\end{abstract}

Key terms epidemiology, lung neoplasms, occupational exposures, titanium dioxide.

Titanium dioxide is a commercially important white pigment. It has a high refractive index, is easily dispersed into a variety of matrices, and is inert during processing and throughout product life (1). It is primarily used as a whitening and opacifying agent in paints, varnishes, lacquers, paper, plastics, ceramics, rubber, and printing ink.

Although occupational exposure to titanium dioxide is extensive, there are few data on the levels and sources of exposure (2), and the data available in the literature are often reported as total dust or nuisance dust and not as titanium dioxide. In 1972, the concentrations of titanium dioxide dust measured during the grinding of the pigment were reported to be in the range $10-400 \mathrm{mg} / \mathrm{m}^{3}$ (3). Long-term exposures to titanium dioxide dust in a titanium pigment production factory occasionally exceeded $10 \mathrm{mg} / \mathrm{m}^{3}$, while exposures greater than $10 \mathrm{mg} / \mathrm{m}^{3}$ were common during the repair of production machinery (4). More recently, it has been reported that a facility manufacturing titanium dioxide had measurements of total respirable dust in the range of $3-10 \mathrm{mg} / \mathrm{m}^{3}$ during the grinding of the finished product and up to $330 \mathrm{mg} / \mathrm{m}^{3}$ in the bagging area (5). Paint-spraying operations entail lower exposure levels. With good ventilation, paint mist levels can generally be controlled to below $10 \mathrm{mg} / \mathrm{m}^{3}$, except in enclosed

1 Unit of Environmental Cancer Epidemiology, International Agency for Research on Cancer, Lyon, France.

2 Department of Medical Epidemiology, Karolinska Institute, Stockholm, Sweden.

3 Institut National de Recherche et de Sécurité (INRS) - Institut Armand-Frappier, Laval, Quebec, Canada.

4 Current address: Unit of Field and Intervention Studies, International Agency for Research on Cancer, Lyon, France.

5 McGill University, Montreal, Quebec, Canada.

Reprint requests to: Dr Paolo Boffetta, International Agency for Research on Cancer, 150 cours Albert-Thomas, 69008 Lyon, France. [E-mail: boffetta@iarc.fr] 
spaces such as vehicle interiors (6). Given that titanium dioxide is generally present in paints in proportions varying between $10 \%$ and $20 \%$ (7), titanium dioxide levels are probably below $2 \mathrm{mg} / \mathrm{m}^{3}$ during most spray paint operations. Nevertheless, spray painting in closed spaces without protection has been shown to lead to the inhalation of high concentrations of titanium (8). Exposure to the rutile coating of rods used in shielded metal arc welding produces low levels of exposure to titanium dioxide, but in fume form instead of as dust (9).

In 1989, the International Agency for Research on Cancer (IARC) evaluated titanium dioxide in its monograph program. The conclusion was that there was inadequate evidence for its carcinogenicity in humans and limited evidence for carcinogenicity in experimental animals. The overall evaluation was that titanium dioxide was not classifiable as to its carcinogenicity in humans (group 3) (10).

We have previously reported summary results of a population-based case-referent study from Montreal, Canada, in which we estimated exposure to a large set of agents and mixtures, one of which was titanium dioxide (11). When cases of other cancers were used as the reference, ever exposure to titanium dioxide was not associated with an increased risk of lung cancer [odds ratio (OR) $1.0,90 \%$ confidence interval $(90 \%$ CI) 0.7 1.5]. However, when exposure to medium or high concentrations and an exposure frequency of at least 5 years and occurring at least 5 years before the interview was considered, the odds ratio for lung cancer was 2.0 (90\% CI 0.6-7.4). These figures are among the few data available in the literature on human cancer risk as a result of titanium dioxide exposure. However, considering the relative importance of this agent, it has become pertinent to review our data and carry out more-detailed analyses. New industrial hygiene data have become available since the mid-1980s, when our initial exposure assessments were carried out. In addition, the initial exposure assessments of titanium dioxide were carried out in the context of a simultaneous assessment of 293 substances, and the opportunity for focusing on titanium dioxide was reduced. Consequently, we decided to review the assessments of exposure to titanium dioxide and other titanium compounds. Furthermore, a more-refined statistical analysis was carried out that focused on the relationship between titanium dioxide and lung cancer.

\section{Subjects and methods}

A case-referent study was conducted during 19791985 in Montreal. The subjects comprised histologically confirmed cases of 19 types of cancer among men aged
35-70 years and diagnosed in all large hospitals in the study area, as well as a sample of the population selected from electoral rolls and by random digit dialing. Interviews were conducted with 3730 cancer patients (82\% response rate) and 533 population referents $(71 \%$ response rate). Over $82 \%$ of the interviews were conducted with the subjects, and proxies were interviewed for the rest. For the purpose of this analysis, we selected 857 cases of lung cancer and two groups of referents, 533 population referents and a subset of 1349 cases of other cancers (cancer referents). We created a third group of controls, by merging the 533 population referents and a random sample of 533 cancer referents, including cases of cancers of the colon and rectum (110), bladder (78), prostate (64), stomach (59) and kidney (40) and also non-Hodgkin's lymphoma (47). We used this third group of referents for most of the analyses. The histological types of lung cancer were squamous cell carcinoma (359), adenocarcinoma (167), small-cell carcinoma (159), and other and unknown (172).

The questionnaire included a section on life-style factors and a semi-structured section designed to obtain a detailed description of each job the subject had held in his work experience. For each job, the subject was asked about the company, its products, the nature of the worksite, his main and subsidiary tasks, and additional information about possible exposures (eg, use of protective devices, equipment maintenance). Interviewers were trained and monitored for the occupational interview. For some occupations, supplementary questionnaires were developed to assist the interviewers with detailed technical probing (12).

A team of industrial hygienists examined each questionnaire and translated each job into a list of potential exposures to 293 agents, including all titanium compounds, titanium dioxide (as dust or mist) and titanium dioxide fumes. The industrial hygienists used different sources for their assessment, including books, journal articles, consultants with familiarity with industries in the Montreal area, as well as the interviews themselves.

The coding consisted of noting, for each agent thought to be present in each job, the duration of exposure and three other dimensions of information, each on the following three-category scale: (i) degree of confidence that the exposure had actually occurred (possible, probable, definite), (i) frequency of exposure expressed as the percentage of normal worktime $(<5 \%$, $5-30 \%,>30 \%$ ), and (iii) the concentration level (low, medium, high). Although it was not possible to attribute quantitative values to the exposure levels, we believe that we were able to ascribe a range of values to each of the three concentration categories. Namely, a low concentration of titanium dioxide corresponded to conditions experienced by arc welders or painters using rollers (as opposed to spray painters) and therefore corre- 
sponded roughly to titanium dioxide concentrations ranging from 0.05 to $1 \mathrm{mg} / \mathrm{m}^{3}$. A medium concentration, such as that which would be experienced by spray painters, corresponded roughly to between 1 and $10 \mathrm{mg} / \mathrm{m}^{3}$. Finally, a high concentration, which was attributed to poorly protected workers involved in grinding or bagging titanium dioxide pigment, was thought to correspond to exposures over $10 \mathrm{mg} / \mathrm{m}^{3}$. As already indicated, an exposure assessment was carried out in the 1980s that addressed 293 substances, including titanium dioxide. For our purposes in the present study, we have reviewed the entire database and focused on titanium dioxide while incorporating recent industrial hygiene data. This procedure has resulted in several changes in the ascribed exposure status.

Within the framework of the expanded exposure assessment, we considered the following three main circumstances of exposure to titanium dioxide and titanium compounds: (i) titanium dioxide production, (ii) the manufacture and use of titanium-dioxide-containing products, mainly paints, and (iii) metal arc welding.

Titanium dioxide is produced from illmenite ore or from titanium slag; Canadian plants use slag exclusively. In the province of Quebec, one plant has produced titanium slag, and two plants have produced the pigment using the sulfate process. Since titanium slag contains a maximum of $85 \%$ titanium dioxide, exposure to the slag was considered in our study as exposure to titanium compounds rather than as exposure to titanium dioxide (this assessment concerned five subjects).

One would expect workers involved in the milling and grinding operations in titanium dioxide production to be the most highly exposed. There is, however, a paucity of data regarding the exposure of these workers to titanium dioxide. In one study, the authors classified jobs in the manufacture of titanium dioxide using the sulfate on a 3-point scale (8). Workers involved in dry milling, digestion, dry calcination, grinding, and packaging were considered exposed at the highest level. In an evaluation of chemical exposure in the manufacturing of titanium dioxide by the sulfate process in three different plants, Hery and his colleagues reported that the highest levels were found in the grinding of the ore and the finished product and in the packaging areas (5). Under normal circumstances, the average measured dust concentrations (respirable fraction, 8-hour personal samples) were between 0.47 and $6.48 \mathrm{mg} / \mathrm{m}^{3}$ in these areas, but concentrations ranging up to 330 (average 40) $\mathrm{mg} / \mathrm{m}^{3}$ were measured in the bagging area of one of the plants.

About one-half of the pigment used in the United States goes into surface coatings; other major consumers are paper manufacturers and the plastic and ceramic industries. Given its widespread use as a pigment in paints, it is not surprising that, in our study, more than half of the subjects exposed to titanium dioxide worked as painters.

A case report of pulmonary alveolar proteinosis for a professional painter suggested that spray painting in closed spaces, while not wearing a protective mask, leads to the inhalation of high concentrations of titanium (8). The patient, a painter with 25 years of experience, had unusually large amounts of titanium dioxide in his lungs (60 to 129 million particles per $\mathrm{cm}^{3}$ ).

In one study of continuous painting operations in a paint booth, paint mist concentrations could generally be controlled below $5 \mathrm{mg} / \mathrm{m}^{3}$ except when internal cavities were sprayed (6). In intermittent nonconveyorized processes, paint mist concentrations ranging from 2 to $320 \mathrm{mg} / \mathrm{m}^{3}$ were reported. With proper ventilation, concentrations could be kept below $10 \mathrm{mg} / \mathrm{m}^{3}$ for these operations except in relatively enclosed spaces (vehicle interiors).

In our study, of the eight jobs classified as highly exposed to titanium dioxide, one involved grinding of the pigments. In the other seven jobs, the workers were involved in the mixing of raw materials in the manufacture of paints or plastic products (floor tiles). Although we have no documentation for support, we believe that it is reasonable to assume that the titanium dioxide levels are as high in these mixing operations as they are in the grinding and bagging areas of the pigment manufacturing facilities.

Finally, several subjects were classified as exposed to titanium dioxide fumes because of the rutile coating on the rods used in shielded metal arc welding to stabilize the arc and to add alloying metal. According to Burgess (9), when rutile electrodes are used, from $3 \%$ to $4.6 \%$ of the total welding fume consists of titanium dioxide. Given that total welding fume in shielded metalarc welding varies from 1 to $25 \mathrm{mg} / \mathrm{m}^{3}$, depending on the efficiency of the ventilation and the degree of enclosure, titanium dioxide fumes can vary from 0.03 to $1.15 \mathrm{mg} / \mathrm{m}^{3}$.

All steps of the exposure assessment were conducted blindly as to the case-referent status of the exposed persons. For the statistical analyses, only subjects with probable or definite exposure for at least 5 years before the interview were classified as exposed, while subjects with possible exposure ( 3 cases and 1 referent, combined group) were excluded from all the analyses. Furthermore, exposure was classified as "substantial" if it lasted for more than 5 years at a medium or high frequency and level; otherwise the exposure was considered "nonsubstantial".

As measures of relative risk, odds ratios and their 95\% confidence intervals $(95 \% \mathrm{CI})$ were computed from unconditional logistic regression models fit by the maximum likelihood method (13). The following variables were included in all the regression models as potential 
Table 1. Distribution of the cases and referents by selected characteristics.

\begin{tabular}{|c|c|c|c|c|}
\hline \multirow[t]{2}{*}{ Characteristic } & \multicolumn{2}{|c|}{$\begin{array}{l}\text { Cases }^{\text {a }} \\
(\mathrm{N}=857)\end{array}$} & \multicolumn{2}{|c|}{$\begin{array}{l}\text { Referents }{ }^{b} \\
(\mathrm{~N}=1066)\end{array}$} \\
\hline & $\mathrm{N}$ & $\%$ & N & $\%$ \\
\hline \multicolumn{5}{|l|}{ Ethnicity } \\
\hline French & 592 & 69 & 657 & 62 \\
\hline Anglophone & 116 & 13 & 159 & 15 \\
\hline Italian & 48 & 6 & 81 & 8 \\
\hline Other European & 75 & 9 & 124 & 12 \\
\hline Other & 26 & 3 & 45 & 4 \\
\hline \multicolumn{5}{|l|}{ Smoking status ${ }^{c}$} \\
\hline Nonsmoker & 9 & 1 & 161 & 15 \\
\hline Current smoker ${ }^{d}$ & 680 & 79 & 588 & 55 \\
\hline Former smoker & 168 & 20 & 317 & 30 \\
\hline \multicolumn{5}{|l|}{ Exposure to asbestos } \\
\hline None & 682 & 80 & 878 & 82 \\
\hline Nonsubstantial & 145 & 17 & 167 & 16 \\
\hline Substantial & 30 & 3 & 21 & 2 \\
\hline \multicolumn{5}{|c|}{ Exposure to benzo(a)pyrene } \\
\hline None & 638 & 74 & 823 & 77 \\
\hline Nonsubstantial & 180 & 21 & 203 & 19 \\
\hline Substantial & 39 & 5 & 40 & 4 \\
\hline \multicolumn{5}{|l|}{ Respondent } \\
\hline Self & 605 & 71 & 894 & 84 \\
\hline Proxy & 252 & 29 & 172 & 16 \\
\hline
\end{tabular}

a Median age: 60 years; median income: CAD 22.43.

b Median age: 61 years; median income: CAD $24.0^{3}$.

c Logarithm cigarettes-years (median): 4.2 for the cases and 3.8 for the referents.

${ }^{d}$ Including former smokers who quit up to 2 years before the interview.

Table 2. Odds ratio of lung cancer for exposure to titanium dioxide. $(O R=$ odds ratio adjusted for age, family income, ethnicity, respondent status, and tobacco smoking, $95 \% \mathrm{Cl}=95 \%$ confidence interval)

\begin{tabular}{|c|c|c|c|c|}
\hline & $\begin{array}{c}\text { Case } \\
\text { (N) }\end{array}$ & $\begin{array}{l}\text { Referents } \\
\text { (N) }\end{array}$ & $\mathrm{OR}$ & $95 \% \mathrm{Cl}$ \\
\hline \multicolumn{5}{|l|}{ Exposure group } \\
\hline $\begin{array}{l}\text { Unexposed } \\
\text { Ever exposure a } \\
\text { Nonsubstantial exposure }^{\text {Substantial exposure }}{ }^{b}\end{array}$ & $\begin{array}{r}821 \\
33 \\
25 \\
8\end{array}$ & $\begin{array}{r}1022 \\
43 \\
34 \\
9\end{array}$ & $\begin{array}{l}1.0 \\
0.9 \\
0.9 \\
1.0\end{array}$ & $\begin{array}{l}. * \\
0.5-1.5 \\
0.5-1.5 \\
0.3-2.7\end{array}$ \\
\hline \multicolumn{5}{|l|}{ Frequency of exposure } \\
\hline $\begin{array}{l}<5 \% \\
5-30 \% \\
>30 \%\end{array}$ & $\begin{array}{r}5 \\
10 \\
18\end{array}$ & $\begin{array}{r}4 \\
17 \\
22\end{array}$ & $\begin{array}{l}1.3 \\
0.7 \\
1.0\end{array}$ & $\begin{array}{l}0.3-5.9 \\
0.3-1.5 \\
0.5-2.0\end{array}$ \\
\hline \multicolumn{5}{|l|}{ Level of exposure } \\
\hline $\begin{array}{l}\text { Low } \\
\text { Medium } \\
\text { High }\end{array}$ & $\begin{array}{r}25 \\
6 \\
2\end{array}$ & $\begin{array}{r}29 \\
9 \\
5\end{array}$ & $\begin{array}{l}0.9 \\
1.0 \\
0.3\end{array}$ & $\begin{array}{r}0.5-1.7 \\
0.3-3.3 \\
0.07-1.9\end{array}$ \\
\hline \multicolumn{5}{|l|}{ Duration of exposure } \\
\hline $\begin{array}{l}1-21 \text { years } \\
\geq 22 \text { years }\end{array}$ & $\begin{array}{l}17 \\
16\end{array}$ & $\begin{array}{l}22 \\
21\end{array}$ & $\begin{array}{l}1.0 \\
0.8\end{array}$ & $\begin{array}{l}0.5-2.0 \\
0.4-1.6\end{array}$ \\
\hline
\end{tabular}

a Three cases and one referent, either classified as exposed with low confidence or as exposed only during the last 5 years, were excluded from the analysis.

b Substantial exposure: medium or high level and frequency $>5 \%$ for at least 5 years, occurring at least 5 years before the interview. confounders: age (as a continuous variable), socioeconomic status, expressed as family income (as a continuous variable), ethnicity (French, Anglo, Italian, Jewish, other European, other), respondent status (self, proxy), tobacco smoking (expressed as the logarithm of cigarette-years and time since quitting smoking), and estimated exposure to asbestos (3 categories) and to benzo(a)pyrene (3 categories).

\section{Results}

Table 1 provides the distribution of the cases and referents by age, family income, ethnicity, respondent status, tobacco smoking, and exposure to asbestos and polycyclic aromatic hydrocarbons. The cases and referents were similar with respect to age and ethnicity. The income of the cases was slightly lower than that of the referents. As expected, the cases smoked more than the referents. Exposure to asbestos and benzo(a)pyrene was slightly more prevalent among the cases than the referents.

Altogether 33 cases $(3.9 \%)$ and 43 referents (4.0\%, pooled set) were classified as ever exposed to titanium dioxide. The odds ratio for ever exposure was 0.9 (95\% CI $0.5-1.5)$ (table 2). The frequency of exposure was $5 \%$ or more for most of the exposed subjects; the level of exposure, on the other hand, was assessed as low for most of the exposed cases and referents (table 2). No clear trend was apparent for either exposure dimension or duration of exposure. We found no evidence of a confounding effect of smoking or exposure to benzo(a)pyrene and asbestos, the odds ratios for substantial exposure to titanium dioxide being 1.1 (crude) and 1.0 (adjusted for age, income, ethnicity and respondent status), as compared with 1.0 (table 2, fully adjusted).

The preceding results were based on the pooling of equal numbers of cancer referents and population referents. We also carried out separate analyses with each reference group. The odds ratio for ever exposure was 0.9 (95\% CI $0.5-1.7$ ) with the population referents and 0.9 (95\% CI 0.5-1.6) with the cancer referents. For substantial exposure, the corresponding estimates were 0.9 (95\% CI $0.3-2.9)$ and 1.1 (95\% CI $0.3-4.5$ ). These results indicate that there was no statistical contraindication to pooling the referents. We therefore placed the greatest confidence in the results obtained using pooled referents.

The analysis by histological type resulted in similar odds ratios for ever exposure to titanium dioxide for squamous cell carcinoma (OR 1.1, 95\% CI 0.6-2.0, 16 exposed cases) and small-cell carcinoma (OR 0.9, 95\% CI $0.4-2.4,6$ cases). The OR for adenocarcinoma was reduced (OR $0.6,95 \%$ CI $0.2-1.8,5$ cases). 
Exposure to titanium dioxide fumes was reported for five cases and one referent (pooled set OR 9.1, 95\% CI $0.7-118)$. The single referent exposed to titanium dioxide fumes was also exposed to titanium dioxide dust, while the five cases exposed to fumes were not classified as exposed to titanium dioxide dust. All the six subjects, except one case, were also exposed to chromium and nickel. Exposure to benzo(a)pyrene was reported for three cases and one referent, and exposure to asbestos was apparent for two cases and one referent. Five cases and four referents were classified as exposed to titanium compounds other than dioxide (OR 1.8, 95\% CI 0.5-7.3), all but one case being classified as exposed at a nonsubstantial level.

\section{Discussion}

Our results do not provide clear evidence of an increase in lung cancer risk among workers exposed to titanium dioxide. The apparent increase in the odds ratio for exposure to titanium dioxide fumes was based on results for six exposed subjects who were also exposed to other carcinogens. Despite the lack of statistical significance, the finding merits attention in future studies.

Exposure misclassification might have resulted in an underestimate of increased risk. We addressed this potential problem by stratifying the exposed workers according to the estimated frequency and level of exposure. Although the number of exposed workers in some of the categories was small, there was no indication of an increased risk in the groups with the highest exposure.

Another approach to assessing the likelihood and extent of exposure misclassification is to consider the odds ratio for exposure to known carcinogens. The odds ratio for substantial exposure to benzo(a)pyrene (adjusted in a fashion similar to those presented in table 2) was 1.3 (95\% CI 0.8-2.1); that for substantial exposure to asbestos was 1.9 (95\% CI 1.0-3.6). This study was therefore able to detect an increased odds ratio for lung cancer following exposure to established carcinogens.

Confounding from other occupational exposures and from extra occupational factors is a concern in population-based studies of lung cancer. We were able to address this problem by including different potential confounders in the regression models. Given the general pattern of null results, however, it is negative confounding which should be of concern (ie, subjects unexposed to titanium dioxide being more likely to be exposed to lung carcinogens), and this is an unlikely event.

Our study had limited power to detect a positive association between exposure to titanium dioxide and lung cancer risk. Given the number of study subjects and a prevalence of ever exposure of $4 \%$ among the referents, the study had a power of $86 \%$ to detect an odds ratio of 2 as statistically significant (alpha $=0.05$ ) and a power of $65 \%$ for an odds ratio of 1.5 .

The evidence for the experimental carcinogenicity of titanium dioxide is based on experiments by inhalation among rats (14-17), the results showing an increased incidence of lung adenomas and of cystic keratinizing lesions diagnosed as squamous-cell carcinomas in animals in high-dose groups. Oral, subcutaneous, intratracheal, and intraperitoneal administration did not produce a significant increase in the frequency of any type of tumor in any rodent species (18-22). However, for hamsters, the combined intratracheal administration of titanium dioxide and benzo(a)pyrene resulted in an increase in the incidence of benign and malignant tumors of the larynx, trachea, and lungs over that in benzo(a)pyrene-treated referents (18).

These experimental results have raised concern about a possible carcinogenic effect on the lung of humans exposed to titanium dioxide. However, the available data on health effects in humans are sparse.

In a cross-sectional study of 209 titanium metal production workers, including 78 workers who were involved in the reduction process and exposed to titanium tetrachloride vapor, titanium oxychloride and titanium dioxide particles, reductions in lung function (forced expiratory volume in 1 minute) were found (23). This finding could be due to exposure to titanium tetrachloride, which reacts violently with water to liberate heat and produce hydrochloric acid, titanium oxychloride, and titanium dioxide. Pleural disease with plaques and pleural thickening was observed in 36 workers, including eight reduction process workers. Some cases were probably caused by prior exposure to asbestos; however, among workers not known to have been exposed to asbestos, the relative risk for pleural disease after more than 10 years of employment was 3.8.

In the only available mortality study, Chen \& Fayerweather (24) studied mortality among 1576 male employees who had been exposed to titanium dioxide for more than 1 year in two plants in the United States. Information on deaths among active and pensioned employees was obtained from the company mortality register. The observed numbers of deaths were compared with rates for the United States. Mortality from all cancers was lower than expected, nine deaths from lung cancer being observed, with 17.3 expected (standardized mortality ratio $0.52,95 \% \mathrm{CI} 0.24-0.99$ ). In a casereferent study nested in this cohort and a further 969 workers from the same plant, with exposure to titanium tetrachloride, no increased risk of lung cancer was found with estimated exposure to either titanium dioxide or titanium tetrachloride (25).

Most of the workers classified as exposed to titanium dioxide in our study were painters and motor vehicle 
mechanics and repairers who were engaged in painting activities. Those classified as highly exposed were mainly involved in the mixing of raw materials in the manufacture of paints or plastic products containing titanium dioxide. Although exposure data are lacking, it is reasonable to assume that exposure levels in these mixing occupations are as high as those encountered in the grinding and bagging areas of titanium dioxide manufacturing plants. Our results are therefore comparable with those of studies of production workers.

The present analysis did not confirm our previous results of a possible increase in lung cancer risk among subjects with high exposure to titanium dioxide (11). This discrepancy is mainly due to improved exposure assessment, although it may also be partially attributable to the use of a different, and we think preferable, reference group.

We conclude that occupational exposure to titanium dioxide is probably not associated with a substantial increase in lung cancer risk. Our results, however, are compatible with a modest increase in risk. Furthermore, a low exposure prevalence and the misclassification of exposure may have contributed to false positive results.

\section{References}

1. Considine DM. Chemical and process technology encyclopedia. New York (NY): McGraw-Hill, 1974:1102—4.

2. Santodonato J, Bosch S, Meylan W, Becker J, Neal M. Monograph on human exposure to chemicals in the workplace: titanium dioxide. Syracuse (NY): Center for Hazard Assessment, Syracuse Research Corporation, 1985. Report no SRCTR-84-804.

3. Elo R, Maatta K, Uksila E, Arstila AU. Pulmonary deposits of titanium dioxide in man. Arch Pathol 1972;94:417-24.

4. Rode LE, Ophus EM, Gylseth B. Massive pulmonary deposition of rutile after titanium dioxide exposure: light-microscopical and physico-analytical methods in pigment identification. Acta Pathol Microbiol Scand 1981;A89:455-61.

5. Héry M, Hecht G, Gerber JM, Bemer D, Gorner P. Fabrication du dioxyde de titane par le procédé sulfurique. Cah Notes Doc 1991;145:693-8.

6. O'Brien DM, Hurley DE. An evaluation of control technology for spray painting. Am Ind Hyg Assoc J 1982;43:695703.

7. Gosselin RE, Smith RP, Hodge HC. Clinical toxicology of commercial products. 5th ed. Baltimore (MD): Williams \& Wilkins, 1984:VI-83.

8. Keller CA, Frost A, Cagle PT, Abraham JL. Pulmonary alveolar proteinosis in a painter with elevated purmonary concentrations of titanium. Chest 1995;108:277-80.

9. Burgess WA. Recognition of health hazards in industry: a review of materials and processes. New York: John Wiley and Sons, 1981.

10. International Agency for Research on Cancer (IARC). Tita- nium dioxide. In: Some organic solvents, resin monomers and related compounds, pigments and occupational exposures in paint manufacture and painting. Lyon: IARC, 1989:307-26. IARC monographs on the evaluation of carcinogenic risks to humans, vol 47.

11. Siemiatycki J. Risk factors for cancer in the workplace. Boca Raton (FL): CRC Press, 1991.

12. Gerin M, Siemiatycki J. The occupational questionnaire in retrospective epidemiologic studies. Appl Occup Environ Hyg 1991;6:495-501.

13. Breslow NE, Day NE. Statistical methods in cancer research; vol 1 (The analysis of case-control studies). Lyon: International Agency for Research on Cancer (IARC), 1980. IARC scientific publications, no 32.

14. Thyssen J, Kimmerle G, Dickhaus S, Emminger E, Mohr U. Inhalation studies with polyurethane foam dust in relation to respiratory tract carcinogenesis. J Environ Pathol Toxicol 1978;1:501-8.

15. Lee KP, Trochimowicz HJ, Reinhardt CF. Transmigration of titanium dioxide (TiO2) particles in rats after inhalation exposure. Exp Mol Pathol 1985;42:331-43.

16. Lee KP, Trochimowicz HJ, Reinhardt CF. Pulmonary response of rats exposed to titanium dioxide (TiO2) by inhalation for two years. Toxicol Appl Pharmacol 1985;79:179_ 92.

17. Lee KP, Henry NW, Trochimowicz HJ, Reinhardt CF. Pulmonary response to impaired lung clearance in rats following excessive TiO2 dust deposition. Environ Res 1986;41:14467.

18. Stenbäck F, Rowland J, Sellakumar A. Carcinogenicity of benzo[a]pyrene and dusts in the hamster lung (instilled intratracheally with titanium oxide, aluminium oxide, carbon and ferric oxide). Oncology 1976;33:29-34.

19. National Cancer Institute (NCI). Bioassay of titanium dioxide for possible carcinogenicity. Bethesda (MD): NCI, 1979. Technical report series, no 97.

20. Bischoff F, Bryson G. Tissue reaction to and fate of parenterally administered titanium dioxide, I: the intraperitoneal site in male Marsh-Buffalo mice. Res Commun Chem Pathol Pharmacol 1982;38:279-90.

21. Maltoni C, Morisi L, Chieco P. Experimental approach to the assessment of the carcinogenic risk of industrial inorganic pigments. In: Englund A, Ringen K, Mehlman MA, editors. Occupational health hazards of solvents. Princeton (NJ): Princeton Scientific Publishers, 1982:77-92. Advances in modern environmental toxicology, vol 2.

22. Pott F, Ziem U, Reiffer FJ, Huth F, Ernst H, Mohr U. Carcinogenicity studies on fibres, metal compounds, and some other dusts in rats. Exp Pathol 1987;32:129—52.

23. Garabrant DH, Fine LJ, Oliver C, Bernstein L, Peters JM. Abnormalities of pulmonary function and pleural disease among titanium metal production workers. Scand J Work Environ Health 1987;13:47-51.

24. Chen JL, Fayerweather WE. Epidemiologic study of workers exposed to titanium dioxide. J Occup Med 1988;30:937-42.

25. Fayerweather WE, Karns ME, Gilby PH, Chen JL. Epidemiologic study of lung cancer mortality in workers exposed to titanium tetrachloride. J Occup Med 1992;34:164-9.

Received for publication: 4 September 2000 